\title{
Antimicrobial activity of synthetic cationic peptides and lipopeptides derived from human lactoferricin against Pseudomonas aeruginosa planktonic cultures and biofilms
}

\author{
Susana Sánchez-Gómez ${ }^{1, *^{*}}$, Raquel Ferrer-Espada', Philip S. Stewart², Betsey Pitts², Karl Lohner ${ }^{3}$ \\ and Guillermo Martínez de Tejada'
}

\begin{abstract}
Background: Infections by Pseudomonas aeruginosa constitute a serious health threat because this pathogen particularly when it forms biofilms - can acquire resistance to the majority of conventional antibiotics. This study evaluated the antimicrobial activity of synthetic peptides based on LF11, an 11-mer peptide derived from human lactoferricin against $P$. aeruginosa planktonic and biofilm-forming cells. We included in this analysis selected $\mathrm{N}$-acylated derivatives of the peptides to analyze the effect of acylation in antimicrobial activity. To assess the efficacy of compounds against planktonic bacteria, microdilution assays to determine the minimal inhibitory concentration (MIC), minimum bactericidal concentration (MBC) and time-kill studies were conducted. The anti-biofilm activity of the agents was assessed on biofilms grown under static (on microplates) and dynamic (in a CDC-reactor) flow regimes.

Results: The antimicrobial activity of lipopeptides differed from that of non-acylated peptides in their killing mechanisms on planktonic and biofilm-forming cells. Thus, acylation enhanced the bactericidal activity of the parental peptides and resulted in lipopeptides that were uniformly bactericidal at their MIC. In contrast, acylation of the most potent anti-biofilm peptides resulted in compounds with lower anti-biofilm activity. Both peptides and lipopeptides displayed very rapid killing kinetics and all of them required less than 21 min to reduce 1,000 times the viability of planktonic cells when tested at 2 times their MBC. The peptides, LF11-215 (FWRIRIRR) and LF11-227 (FWRRFWRR), displayed the most potent anti-biofilm activity causing a 10,000 fold reduction in cell viability after $1 \mathrm{~h}$ of treatment at 10 times their MIC. At that concentration, these two compounds exhibited low citotoxicity on human cells. In addition to its bactericidal activity, LF11-227 removed more that $50 \%$ of the biofilm mass in independent assays. Peptide LF11-215 and two of the shortest and least hydrophobic lipopeptides, DI-MB-LF11-322 (2,2-dimethylbutanoyl-PFWRIRIRR) and DI-MB-LF11-215, penetrated deep into the biofilm structure and homogenously killed biofilm-forming bacteria.
\end{abstract}

Conclusion: We identified peptides derived from human lactoferricin with potent antimicrobial activity against $P$. aeruginosa growing either in planktonic or in biofilm mode. Although further structure-activity relationship analyses are necessary to optimize the anti-biofilm activity of these compounds, the results indicate that lactoferricin derived peptides are promising anti-biofilm agents.

Keywords: Antimicrobial peptides, Lactoferricin, Pseudomonas aeruginosa, Biofilm

\footnotetext{
* Correspondence: ssanchez@bionanoplus.com

'Department of Microbiology, University of Navarra, Irunlarrea 1, E-31008 Pamplona, Spain

${ }^{4}$ Present address: Susana Sánchez-Gómez, Bionanoplus, 31110 Noain, Spain

Full list of author information is available at the end of the article
} 


\section{Background}

Pseudomonas aeruginosa is intrinsically resistant to many antibiotics, such as penicillins, first, second and third generation cephalosporines (except ceftazidime), tetracyclins and rifampicin. Resistance is due to the low permeability of its membrane, the presence of efflux pumps and the production of AmpC, a chromosomal $\beta$-lactamase [1]. Furthermore, this pathogen has a notorious ability to acquire additional mechanisms of resistance including those based on efflux pump overexpression, porin loss, alteration of drug target or enzymatic modification of antibiotics. This phenomenon frequently gives rise to clinical isolates displaying a multidrug-resistant phenotype that delays the appropriate antibiotic treatment and leads to therapeutic failure $[1,2]$.

The ability of $P$. aeruginosa cells to form biofilms during infection greatly facilitates its persistence inside the host and contributes to antibiotic resistance [3]. Biofilm formation first requires bacterial cell attachment to a surface followed by the development of a sessile colony with an extracellular matrix containing exopolysaccharide, proteins and nucleic acids. P. aeruginosa can form biofilms both in biotic (e.g. lung tissue in cystic fibrosis patients) and abiotic surfaces (e.g. indwelling medical devices). It is estimated that up to $65 \%$ of bacterial infections are associated with the presence of biofilms [1-3]. In addition, biofilms are extremely resistant to antibiotics and immune system effectors [4,5]. All these facts, underscore the importance of developing new therapies against biofilms formed by $P$. aeruginosa. Ideally, new drugs should have multiple mechanisms of action and low susceptibility to the development of resistance, compared to conventional antibiotics.

The antibiotic resistance of biofilm-producing bacteria has been attributed to a diversity of factors including the permeability barrier conferred by the exopolysaccharide, the altered chemical microenvironment within the biofilm (i.e. low oxygen concentration, waste product accumulation and acidic $\mathrm{pH}$ ), the physiological heterogeneity of the bacterial population and the emergence of "persistent" cells [6].

Antimicrobial peptides (AMPs; e.g. nisin, indolicidin, cecropin, magainin, lactoferricin) are produced by a wide variety of organisms as a first line of defense. Their principal mechanism of action involves binding to conserved structural components of the bacterial envelope (e.g. lipopolysaccharide and lipoteichoic acid of Gram-negative and Gram-positive bacteria, respectively) followed by an interaction with the bacterial membrane that can be rapidly lethal. Some AMPs also bind to intracellular targets and inhibit essential biological processes including cell wall formation or DNA, RNA and protein synthesis $[7,8]$. This mechanism of action is rapidly bactericidal and decreases the chances of resistance development compared to conventional antibiotics $[9,10]$.
The heterogeneity of bacteria embedded in the biofilm, a mixture of metabolically active and inactive cells, greatly reduces the efficiency of beta-lactams, which only kill actively dividing cells. In contrast, AMPs are bactericidal independently of the growing state of the target cell, (for a review see [11]) and this increases their appeal as potential anti-biofilm agents.

Lactoferricin is an AMP derived by pepsin digestion of lactoferrin, a multifunctional component of the innate immune system present in milk and other body fluids. Lactoferricin displays antimicrobial activity against a wide variety of microorganisms [12, 13]. Using rational design, we devised a peptide library based on the sequence of LF11, an 11-mer peptide derived from human lactoferricin, and determined the structural features governing the antimicrobial activity of the peptides against planktonic bacteria [14-17]. In the present article, we test the efficacy of these compounds against biofilms formed by $P$. aeruginosa under static and dynamic growth regimes. In these assays, we include acyl-derivatives of the parental compounds to deduce the contribution of the acyl group to the anti-biofilm activity.

\section{Results}

\section{Antimicrobial activity on planktonic $P$. aeruginosa cells}

To assess the antimicrobial activity of the peptides and lipopeptides against planktonic $P$. aeruginosa susceptibility assays consisting of $\mathrm{MIC} / \mathrm{MBC}$ determination combined with killing kinetics studies were performed. Compounds displayed a wide range of antimicrobial efficacy (Table 1) with MICs varying from 8 to $128 \mu \mathrm{g} / \mathrm{ml}$. Interestingly, except for two peptides, LF11-215 and LF11-322, the rest of the compounds were bactericidal at their MIC (i.e. $\mathrm{MIC}=\mathrm{MBC}$ ). As judged by MIC value, the least potent antimicrobials were the two acylated derivatives of peptide LF11-227, whereas a non-acylated compound, LF11-324, showed the best MIC.

In order to evaluate the bactericidal activity of the compounds, the kinetics of killing by each agent was measured at the following concentrations: 1,2 and 4 times its respective planktonic MIC (1X, $2 \mathrm{X}$ and $4 \mathrm{XMIC})$. Table 1 shows the time required by each compound to decrease 3 logs the initial inoculum $\left(\mathrm{T}_{3 \log }\right)$. These assays revealed the rapid kinetics of killing mediated by most of the compounds. Notably, all peptides and lipopeptides except LF11-324 required less than $40 \mathrm{~min}$ at their $\mathrm{MBC}$ to reduce $3 \log$ the initial inoculum. At 2 or $4 \times \mathrm{MIC}$, most of the agents exhibited a very rapid killing, with $\mathrm{T}_{3 \log }$ lower than $20 \mathrm{~min}$. In accordance with these results, time-kill assays (Fig. 1) demonstrated that acylation resulted in an enhanced bactericidal activity, since compounds killed significantly faster than their parental non-acylated counterparts when all were tested at their respective MBC. 
Table 1 Relevant characteristics of peptides and lipopeptides used in this study

\begin{tabular}{|c|c|c|c|c|c|c|c|c|}
\hline \multirow[t]{2}{*}{ Peptides $^{a}$} & \multirow[t]{2}{*}{ Sequences } & & \multirow[t]{2}{*}{$\begin{array}{l}\mathrm{MIC} \\
(\mu \mathrm{g} / \mathrm{ml})\end{array}$} & \multirow[t]{2}{*}{$\begin{array}{l}\mathrm{MBC}^{\mathrm{C}} \\
(\mu \mathrm{g} / \mathrm{ml})\end{array}$} & \multicolumn{3}{|c|}{$\begin{array}{l}T_{3 l o g}^{d} \text { at different concentrations } \\
\text { higher their MICs (minutes) }\end{array}$} & \multirow[t]{2}{*}{$\begin{array}{l}\text { Hydrophobicity } \\
\Delta g_{\text {woct }}(\mathrm{kcal} / \mathrm{mol})\end{array}$} \\
\hline & & & & & $1 X$ & $2 X$ & $4 X$ & \\
\hline LF11-215 & & FWRIRIRR & 64 & 128 & $>360$ & 28 & 10 & 5,5 \\
\hline O-LF11-215 & octanoyl & FWRIRIRR & 32 & 32 & 17 & 21 & 10 & 3,2 \\
\hline DI-MB-LF11-215 & 2,2-dimethylbutanoyl & FWRIRIRR & 16 & 16 & 17 & 11 & 10 & 3,2 \\
\hline 6-MO-LF11-215 & 6-methyloctanoyl & FWRIRIRR & 64 & 64 & 34 & 11 & 10 & 3,2 \\
\hline LF11-322 & & PFWRIRIRR & 32 & 64 & $>360$ & 11 & 11 & 5,64 \\
\hline DI-MB-LF11-322 & 2,2-dimethylbutanoyl & PFWRIRIRR & 32 & 32 & 12 & 11 & 10 & 3,34 \\
\hline 6-MO-LF11-322 & 6-methyloctanoyl & PFWRIRIRR & 64 & 64 & 41 & 39 & 19 & 3,34 \\
\hline LF11-324 & & PFFWRIRIRR & 8 & 8 & 113 & 13 & 10 & 3,93 \\
\hline LF11-227 & & FWRRFWRR & 64 & 64 & 13 & 12 & 10 & 3,94 \\
\hline O-LF11-227 & octanoyl & FWRRFWRR & 128 & 128 & 10 & 10 & 10 & 1,64 \\
\hline 6-MO-LF11-227 & 6-methyloctanoyl & FWRRFWRR & 128 & 128 & 10 & 10 & 10 & 1,64 \\
\hline
\end{tabular}

${ }^{a}$ : Peptide derivatives from human lactoferricin (based on residues 21-31), C-termini is amidated in all peptides; ${ }^{\mathrm{b}}$ : Minimal inhibitory concentration against PAO1 planktonic cells; ${ }^{c}$ : Minimal bactericidal concentration against PAO1 planktonic cells; ${ }^{d}: T_{3 l o g}$ is defined as the time needed to decrease 3 logs the initial inoculum determined in the killing curves assays. Relevant peptide modifications are shown in bold. ${ }^{e}$ :Peptide hydrophobicity is expressed as transfer free energy of peptides from water to n-octanol $\left(\Delta G_{\text {woct }}\right)$ using Wimley-White octanol whole-residue scales [59] taking into account end group contributions, i.e. amidation of the C-termini and where appropriate acylation of N-termini. Latter was approximated by an acetyl group. Calculations were performed using MPEx [60]. Note that this parameter is inversely proportional to hydrophobicity

Compounds with the lowest MBC (e.g. LF11-324) did not correspond to those with the fastest killing kinetics. Paradoxically, agents that killed most rapidly were those lipopeptides that had been found to have the poorest MICs (O-LF11-227, 6-MO-LF11-227).

\section{Antimicrobial activity against $P$. aeruginosa biofilms}

The anti-biofilm activity of the compounds was determined on biofilms grown under static or dynamic flow regimes. On biofilms grown in microplates (i.e. static conditions), the disinfection and removal activities of the agents at 10XMIC were determined by assays based on respiratory rate (MTT test; 3-(4,5-dimethylthiazol-2-yl)2,5-diphenyltetrazolium bromide), and biomass quantification (CV test; crystal violet test), respectively. Results of these experiments are summarized in Fig. 2a. Only LF11-227 and DI-MB-LF11-215 showed a removal activity higher than $35 \%$. Interestingly, two non-acylated compounds, LF11-215 and LF11-227, were found to be the most potent bactericidal agents killing almost $100 \%$ of the biofilm forming bacteria after $24 \mathrm{~h}$ of incubation. Other peptides and lipopeptides (LF11-324, DI-MBLF11-215 and DI-MB-LF11-322) displayed a mediumrange disinfection activity, whereas LF11-322 showed no anti-biofilm activity.

The antimicrobial activity of the compounds was also evaluated on $P$. aeruginosa biofilms grown under dynamic flow conditions by fluorescent microscopy. For this purpose, biofilms were grown on coupons in a CDC-reactor until reaching a bacterial density of $7.63 \mathrm{log} \mathrm{CFU} / \mathrm{cm}^{2}$ and then coupons were incubated during $60 \mathrm{~min}$ with 10XMIC of the corresponding compound. Viable cells of the strain used for these assays emit green fluorescence due to the expression of GFP (green fluorescence protein). To better distinguish between dead and live cells, PI (propidium iodide) was added to the samples. This dye only penetrates inside biofilms when cells are dead or damaged. When this occurs, PI interacts with DNA, and cells emit red fluorescence. Representative fluorescent micrographs of peptide and lipopeptide treated biofilms are shown in Fig. 2b. Despite the disparate methodologies and incubation times used for static and dynamically grown biofilm analysis ( $24 \mathrm{~h}$ vs. $60 \mathrm{~min}$, respectively), several compounds were identified as having potent anti-biofilm activity under both conditions including LF11-215, LF11-324, DI-MBLF11-322, and LF11-227. Due to the significant removal activity displayed by LF11-227 and DI-MB-LF11-215 (see above), it is possible that the microscopic analysis had underestimated the bactericidal activity of these two agents. The only acylated compounds that rivaled the anti-biofilm activity of. LF11-215 and LF11-227 were DI-MB-LF11-322 and DI-MB-LF11-215. Interestingly, those two lipopeptides share the same acyl group (2,2-dimethylbutanoyl). In striking contrast, the parental peptide LF11-322 displayed no anti-biofilm activity compared to their acylated derivatives.

After this preliminary screening, compounds with medium or high-range antimicrobial activity were selected to further characterize their activity against biofilms grown under dynamic conditions in the CDC-reactor. In these assays, mature biofilms were exposed to antimicrobials at different concentrations (1X, $2 \mathrm{X}$ and 10XMIC during $60 \mathrm{~min}$ or $10 \mathrm{XMIC}$ during $10 \mathrm{~min}$ ) and the bactericidal effect was quantified by viable cell count and by confocal laser scanning microscopy (CLSM). 


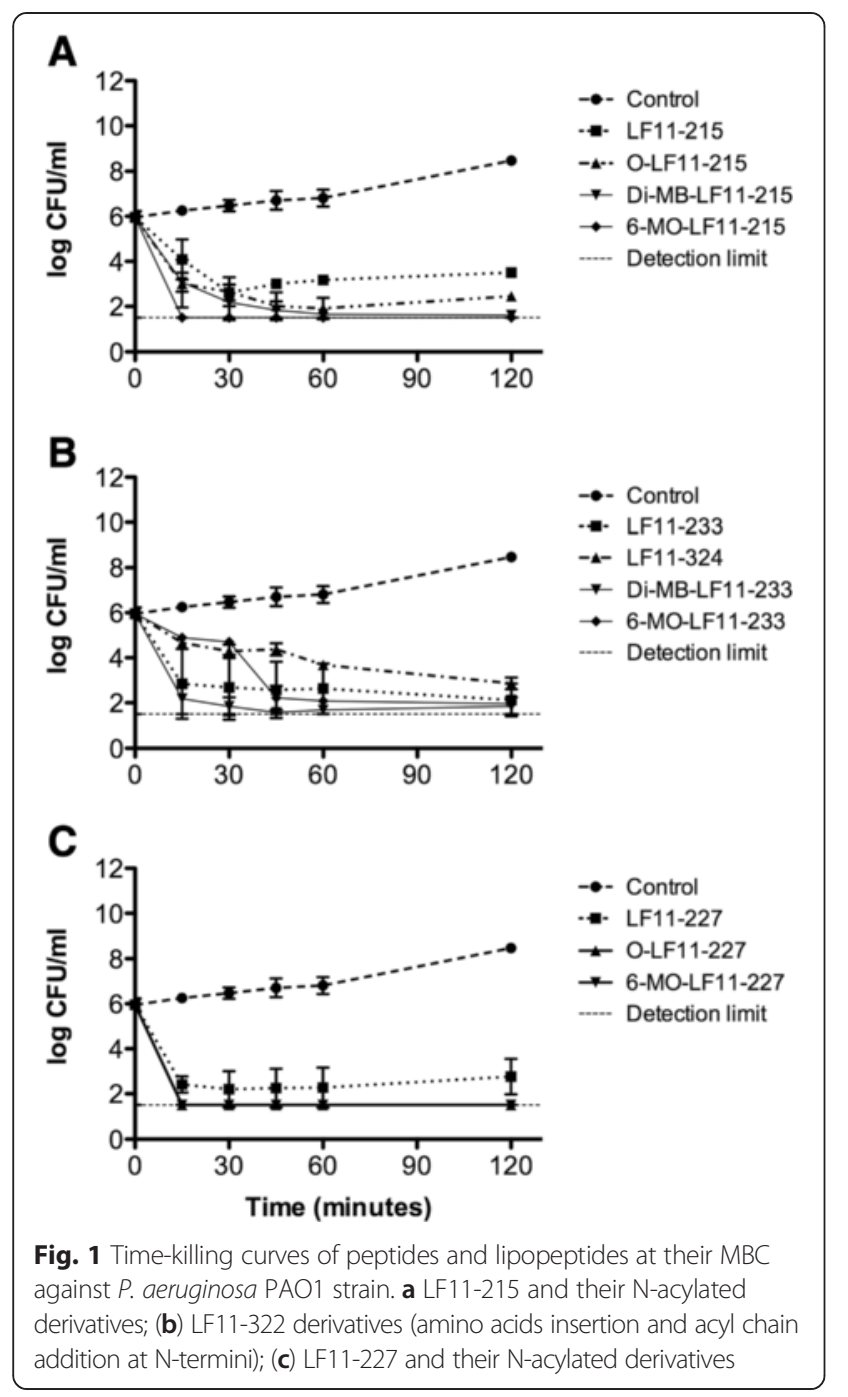

Viable count analysis, summarized in Fig. 3, showed that the anti-biofilm activity of compounds increases in a concentration-dependent manner. Overall, when tested on biofilms grown under dynamic conditions the antibacterial activity of the compounds was similar to that measured on statically cultured biofilms. LF11-215 and LF11-227 were the most potent peptides, since, when added at 10XMIC, they were able to decrease more than 2 logs (i.e. > $99 \%$ ) the cell viability of biofilms in just 10 min. Furthermore, both peptides caused a 10,000 fold reduction in biofilm cell viability after $1 \mathrm{~h}$ of treatment at 10XMIC.

Cytotoxicity of the compounds that displayed the best anti-biofilm activity was evaluated. LF-227, LF11-324, LF11-215 and its acyl derivative Di-MB-LF11-215, showed LC50 values higher than the maximum concentration assayed (10 times their MIC). On the contrary the lipopeptide Di-MB-LF11-322 was more cytotoxic (LC50 = $80 \mu \mathrm{g} / \mathrm{ml}$, nearly 2XMIC value).
Compared to LF11-215 and LF11-227, the rest of the agents reduced viability to a lower extent and displayed a similar anti-biofilm activity regardless of the incubation time. The latter observation may reflect that these agents do not penetrate well inside the biofilm or that they display a rather slow killing mechanism on these structures.

To study these hypotheses, we treated biofilms with the selected compounds at 10XMIC for $60 \mathrm{~min}$ and then quantified by CLSM the percentage of viable (green) vs. dead (red) cells in the entire biofilm volume. As shown in Fig. 4, treatment with LF11-215 resulted in a uniform loss of viability in the whole biofilm structure (inner and outer layers; $100 \%$ of red cells). Similar results were found with DI-MB-LF11-322 (99.81\%), although an inner layer of viable cells was detected. Compared to these two compounds, the rest of the peptides and lipopeptides displayed a lower anti-biofilm activity of similar magnitude (around $50 \%$ of mortality). Finally, biofilms treated with LF11-324 and DI-MB-LF11-215 presented yellow cells. This phenomenon could be potentially explained by the existence of a cluster of permeabilized cells with reduced ability to exclude PI.

\section{Discussion}

In the present study, we have identified short cationic peptides and lipopeptides derived from human lactoferricin that display rapid antimicrobial activity against $P$. aeruginosa planktonic and biofilm-forming cells. Some compounds penetrated deep into biofilm structures and killed homogenously even the inner layers of biofilm cells, as revealed by confocal microscopy analysis.

Acylation enhanced the bactericidal activity of the parental peptides and resulted in lipopeptides that were uniformly bactericidal at their MIC. The compound with the best inhibitory activity was peptide LF11-324 (MIC $=8$ $\mu \mathrm{g} / \mathrm{ml})$. Interestingly, this antimicrobial activity did not vary when the compound was tested on the multiresistant $P$. aeruginosa clinical isolate PS4 [15]. Our results show that the presence of proline $\left(\mathrm{P}^{1}\right)$ at the $\mathrm{N}$-terminus of LF11-322 slightly improves peptide activity (in comparison with LF11-215). Similarly, the addition of another phenylalanine $\left(\mathrm{F}^{2}\right)$ to LF11-322, greatly improves antimicrobial activity (see compound LF11-324) with an 8-fold increase in MIC (LF11-215 vs. LF11-324). These observations correlate with those of Zorko and collaborators, who analyzed the structure of peptide LF11-322 in lipidic environment [18]. According to these authors, the N-terminal residues $\mathrm{P}, \mathrm{F}$ and $\mathrm{W}$ form an essential part of the peptide hydrophobic cluster, a region that upon insertion into the bacterial membrane determines the peptide ability to perturb the phospholipid bilayer.

The incorporation of an acyl group into the peptide structure resulted in a compound with improved inhibitory activity (MIC) only in the case of DI-MB-LF11-215, 


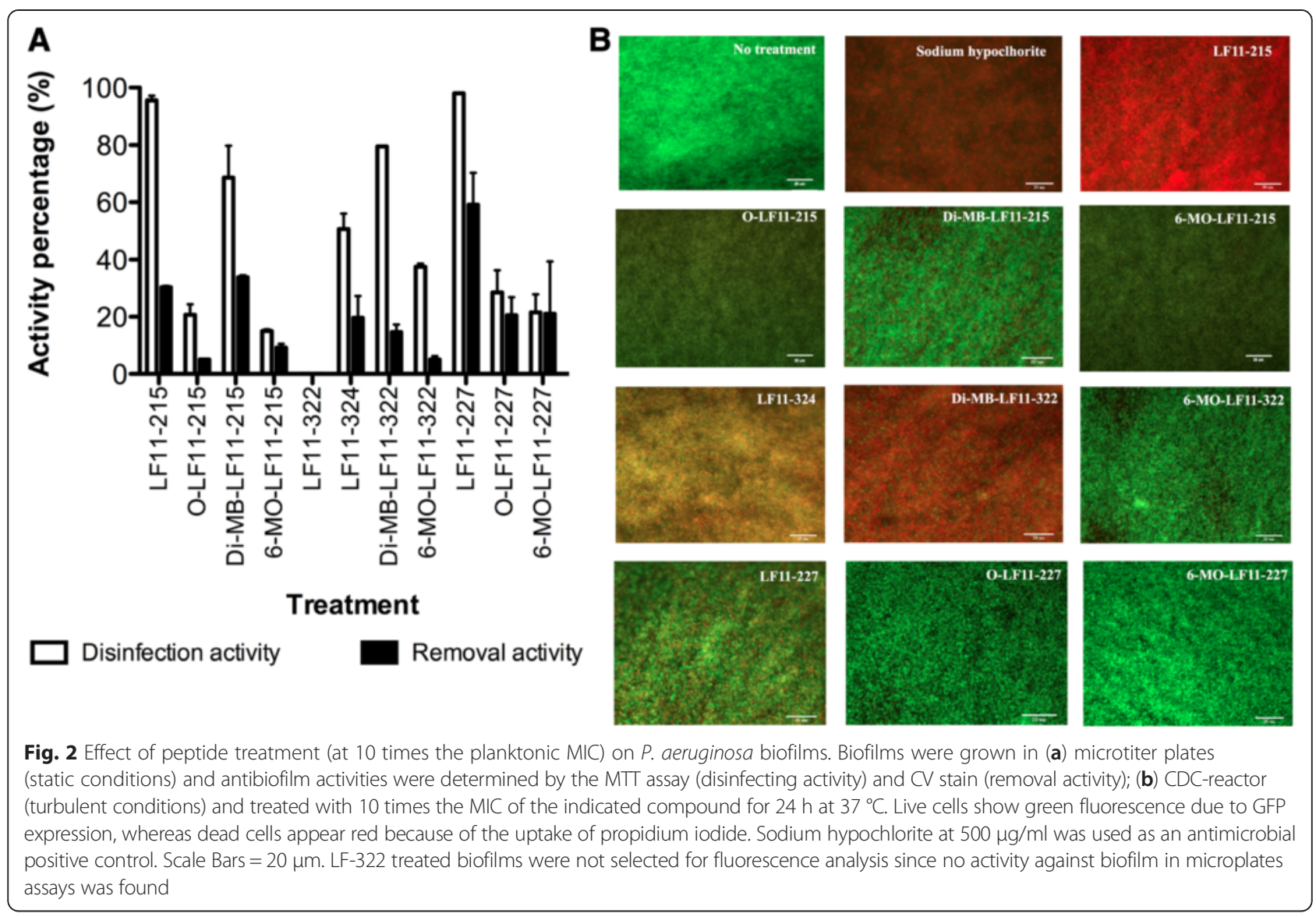

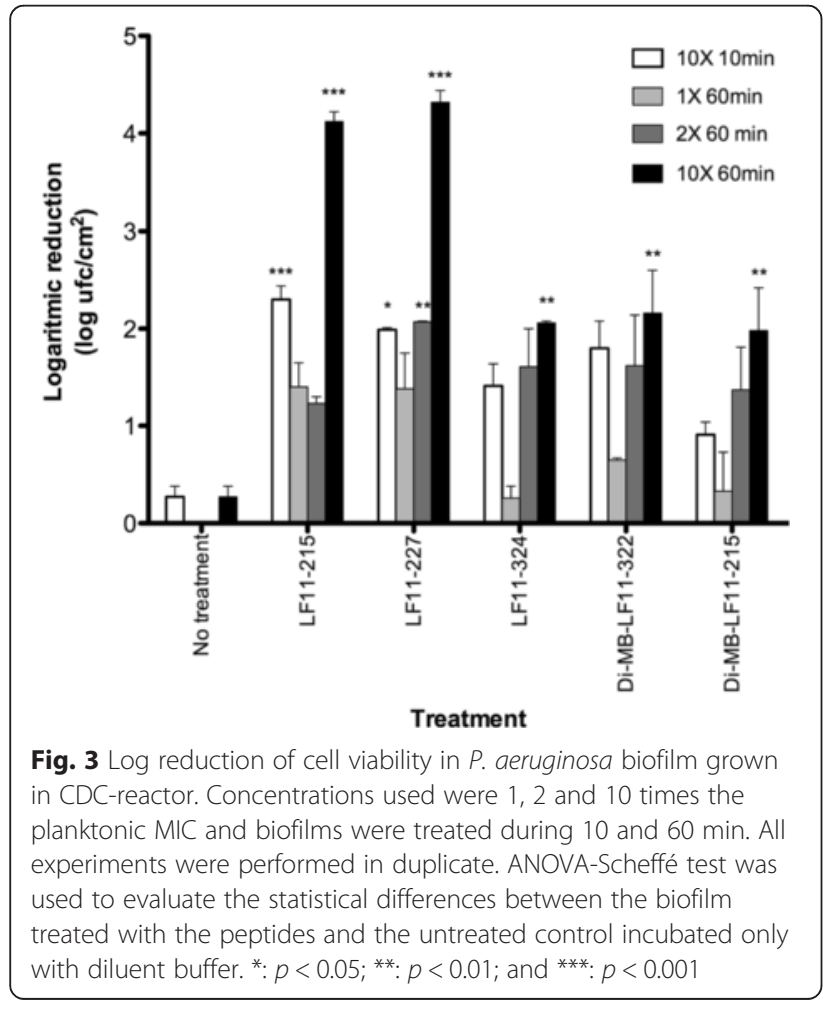

whereas the same acylation had a neutral impact on LF11322 and LF11-227 activity. Although some authors reported that the $\mathrm{N}$-acylation of LF11 with a lauryl group results in a compound with increased antimicrobial activity [19-21], we cannot extend this conclusion to the acylated derivatives tested here in terms of inhibitory activity.. Moreover, $\mathrm{N}$-acylation enhances the binding to lipopolysaccharides of the outer membrane of Gramnegative bacteria to different degrees, which can counteract membrane permeabilization by reducing the effective peptide concentration at the inner membrane $([16,22])$. Another explanation for this discrepancy could be the fact that we used a Gram-negative organism in our assays. Thus, it has been demonstrated ([23]) that although peptide acylation could not improve the antimicrobial efficacy on Gram-negative organisms, it normally enhances this activity against Gram-positive bacteria. In agreement with this observation, we demonstrated that 6-MO-LF11-227 displayed a MIC eight times lower against $S$. aureus compared with its non-acylated counterpart, whereas such acylation did not improve antimicrobial activity against $P$. aeruginosa (data not shown).

It is likely that other features related with the spatial location or conformation of the substituent, the amphipathicity of the resulting lipopeptide or its interfacial activity 

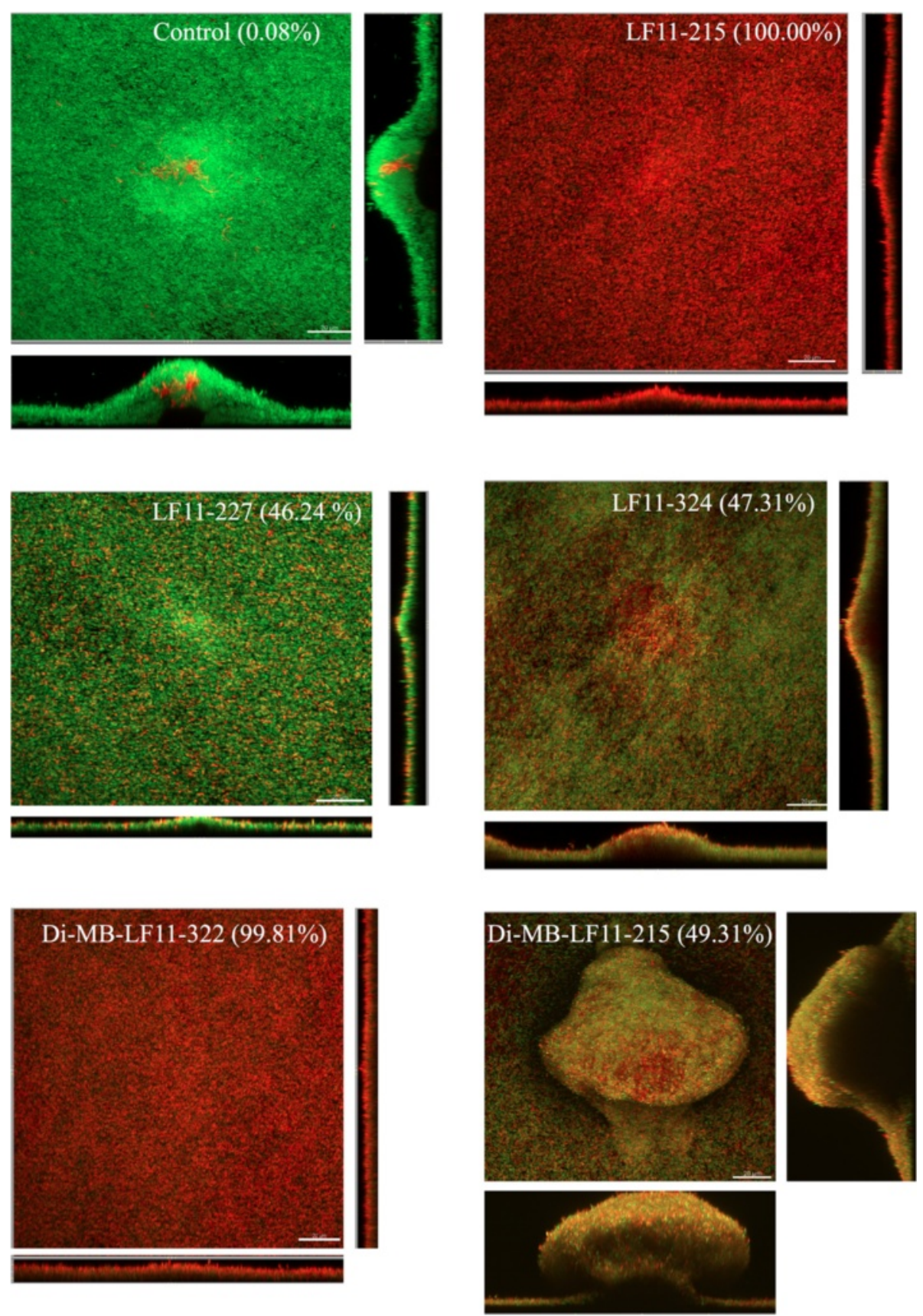

Fig. 4 Bactericidal effect of peptides against $P$. aeruginosa biofilm grown in turbulent flow conditions (CDC-reactor). Antimicrobial activity was observed with CLSM. Live cells emit green fluorescence (due to GFP) and dead cells appear red (due to PI uptake). These images show control biofilm (no peptide treatment) and treated biofilm for $1 \mathrm{~h}$ at 10 times the MIC of peptides. The percentage shown in each image represented the percentage of dead cells (determined by volume). Scale Bars $=20 \mu \mathrm{m}$

have a great impact on the antimicrobial activity, as shown by others [24-27]. In addition, several authors reported that there is an optimum hydrophobicity window resulting in high antimicrobial activity and that any further increment or decline beyond that window dramatically decreases antimicrobial activity [28-30]. Similar observations were reported regarding the number of positive charges [24, 31].
Our results indicate that not only the acyl chain of lipopeptides plays an important role in the antimicrobial activity, but also the amino acid sequence. Time-kill assays performed with the 3 lipopeptides sharing identical acyl group (6-methyloctanoyl) revealed major differences in kinetics with compound 6-MO-LF11-227 being the fastest acting of all (Table 1 and Fig. 1). This agent has additional 
hydrophobic residues in its sequence (F and W) supporting the importance of hydrophobicity balance in antimicrobial activity, as discussed above.

Several studies reported the efficacy of AMPs or peptidomimetics against fungal and bacterial biofilms including those formed by $P$. aeruginosa [32-36]. Although lactoferrin is able to inhibit biofilm formation [37-39] and several investigations evaluated the inhibitory effects of derivatives of lactoferrin against biofilm generated by Gram-negative or Gram-positive organisms [40-45], to the best of our knowledge there are no reports characterizing the antimicrobial activity of lactoferrin derived peptides against $P$. aeruginosa biofilms.

To be useful against mature biofilms, antimicrobials must possess either disinfection activity (i.e. be bactericidal) or removal capacity. In assays on biofilms formed under static conditions (in microplates), we identified several peptides and lipopeptides that decreased more than $50 \%$ cell viability in comparison with non-treated biofilms, whereas one peptide, LF11-227, was able to remove almost $60 \%$ of the biofilm mass. It is possible that the high removal efficacy of this peptide (detected in microplate assays) may have prevented the visualization of more dead cells in fluorescence micrographs of LF11227 treated biofilms. This phenomenon could also explain why DI-MB-LF11-215, another compound with a significant anti-biofilm activity, had an apparently low anti-biofilm activity when assessed by microscopy. Nevertheless, it is likely that the different methodologies used in those two types of assays, namely microplate (static conditions; $24 \mathrm{~h}$ of exposure) vs. CDC reactor (dynamic flow regime; $1 \mathrm{~h}$ ) could explain the observed discrepancies in anti-biofilm activity.

Assays performed with biofilm grown under dynamic conditions confirmed that LF11-215 and LF11-227 were the agents with the most potent bactericidal activity being able to reduce 10,000 times the number of viable biofilm cells and displayed low cytotoxicity when tested at 10XMIC. Although those peptides have poor antimicrobial activity against planktonic cells $(\mathrm{MIC}=64 \mu \mathrm{g} / \mathrm{mL})$, they exert very potent anti-biofilm activity at only 10 times their planktonic MIC. Apart from direct killing, these agents might operate by additional uncharacterized antibiofilm mechanisms. Thus, Fuentes-Nuñez and col. identified peptides that despite having high MICs displayed good anti-biofilm activity. These compounds acted by inhibiting a cellular stress response or by dysregulating genes related with biofilm formation, supporting the notion that antimicrobial and antibiofilm activity should be separately evaluated [46, 47].

We also observed regardless of the biofilm model used, that acylation led to a partial loss of the peptide antibiofilm activity in the case of LF11-215 and LF11-227 derivatives. Interestingly, the lipopeptides that displayed the best activity against biofilms were DI-MB-LF11-322 and DI-MB-LF11-215, that share the same acyl group (2,2dimethylbutanoyl), which were the smallest and among the least hydrophobic of the acylated compounds (see Table 1). Compared to other lipopeptides, it is likely that 2,2-dimethylbutanoyl bearing compounds could penetrate deeper into the biofilm matrix than the others. The low anti-biofilm efficacy of hydrophobic compounds could be due to their tendency to interact with EPS components of $P$. aeruginosa biofilms. Thus, high local concentrations of lipopeptides on EPS matrix may promote their aggregation and hinder their penetration. This limitation could theoretically explain the similar anti-biofilm activity detected with the least active peptides (DI-MB-LF11-322 and DI-MB-LF11-215 and LF11-324) at 2 and 10 times their MIC (Fig. 3). Among these peptides, Di-MB-LF11-322 showed certain toxicity, but other anti-biofilm treatment such as antibiotic lock therapy could be an alternative, since antibiotics are not in contact with tissues or patients bloodstream.

Moreover, LF11-324 treated biofilm showed the presence of yellow cells. This might indicate that although cell membranes are damaged, thus allowing the entry of PI, cells remain still alive and emit green fluorescence, explaining the yellow appearance. This permeabilizing effect was previously described by other authors using an unrelated peptide [48], that was reported to be partially bactericidal. This fact together with previous studies by our group that demonstrated synergistic combination between LF11-215 or LF11-227 and antibiotics in planktonic cultures [15], suggests that combination of lactoferricin derived peptides and antibiotics could enhance the efficacy of peptides as anti-biofilm agents [49]. The use of combinations of antimicrobials (AMPs and non-AMP related antimicrobials) as anti-biofilm therapy has already been successfully tested. This approach entailed not only the use of antimicrobials that target biofilm cells in different metabolic states $[50,51]$ but also the induction of antibiotic uptake due to the membrane disruption caused by another compound $[52,53]$.

\section{Conclusions}

We identified peptides derived from human lactoferricin with potent antimicrobial activity against $P$. aeruginosa growing either in planktonic or in biofilm mode. In general, acylation of peptides increased the bactericidal activity against planktonic bacteria but reduced the antibiofilm potency. Peptides and some of the least hydrophobic lipopeptides were able to kill efficiently biofilm forming cells of $P$. aeruginosa and to penetrate deep into the innermost layers of the biofilm matrix. Both peptides and lipopeptides displayed very rapid killing kinetics and all of them required less than 21 min to reduce 1,000 
times the viability of planktonic cells when tested at 2 times their MBC.

Small and amphipathic cationic peptides are promising anti-biofilm agents, not only due to their broad activity spectrum, rapid mechanism of action and less susceptibility to resistance development, but also to their potential bactericidal activity against slow growing or even non-growing bacteria. Further structure-activity relationship analyses are necessary to optimize the anti-biofilm activity of lipopeptides.

\section{Methods}

\section{Bacterial strains}

Pseudomonas aeruginosa PAO1 was grown at $37{ }^{\circ} \mathrm{C}$ in LB (Luria Bertani, Pronadisa, Madrid, Spain) or TSB (tryptic soy broth, BioMériux, Marcy l'Etoile, France) broth or supplemented with agar (Pronadisa, AlconbendasMadrid, Spain). When PAO1 pMF230 (GFP-expressing PAO1) [54] was grown, TSB was supplemented with $150 \mu \mathrm{g} / \mathrm{ml}$ of carbenicillin.

\section{Peptides}

Peptides were synthesized with an amidated C-terminus by Polypeptide (Strasbourg, France) using 9-fluorenylmethyloxycarbonyl (Fmoc) solid phase chemistry and purified by RP-HPLC (Vydac C18 column; $0.1 \%$ TFA/ water; Beckman Coulter, Danvers, MA, USA). Mass spectroscopy analysis (Reflex IV, Bruker, Bremen, Germany) verified that their purity was $>96 \%$. Peptides sequences are shown in Table 1.

\section{Susceptibility assays on planktonic cells MIC and MBC determination}

Minimal inhibitory concentrations (MIC) of the peptides were determined in Mueller Hinton $(\mathrm{MH})$ medium (Difco Laboratories, Detroit, MI, USA) by the broth microdilution assay following recommendations of the Clinical and Laboratory Standards Institute (CLSI, formerly NCCLS) with some modifications [14]. Minimum bactericidal concentration $(\mathrm{MBC})$ was defined as the concentration that caused a 3-log viability decrease in the initial inoculum and was calculated by colony counts on TSA plates incubated for $24 \mathrm{~h}$ at $37^{\circ} \mathrm{C}$.

\section{Time-kill curves}

Time-kill studies were determined with glass tubes containing $10 \mathrm{ml}$ of $\mathrm{MH}$ and different concentrations of the peptides (1, 2 and 4 times their MIC). Overnight cultures of $P$. aeruginosa PAO1 in TSB were adjusted at $5 \times 10^{7} \mathrm{CFU} / \mathrm{ml}$ turbidimetrically. This biofilm suspension was diluted in the $\mathrm{MH}$ tubes $(1: 50)$ for the timekill assay. Tubes were incubated at $37{ }^{\circ} \mathrm{C}$ with shaking and samples were taken at the following time points after the beginning of incubation: $15 \mathrm{~min}, 30 \mathrm{~min}$,
$45 \mathrm{~min}, 1 \mathrm{~h}, 2 \mathrm{~h}, 4 \mathrm{~h}$ and $6 \mathrm{~h}$. Each sample was serially diluted and plated. The lower limit of detection was $30 \mathrm{CFU} / \mathrm{ml}\left(1.5 \times \log _{10} \mathrm{CFU} / \mathrm{ml}\right)$. Previous experiments demonstrated that the carryover effect of the peptides in the most concentrated dilution used for viable counts (a $10^{-1}$ dilution) was negligible.

To quantify the killing efficiency of the treatments, the parameter $\mathrm{T}_{3 \log }$ (defined as the time required for the treatment to decrease 3 logs the initial inoculum) was used.

\section{Susceptibility assays on biofilms Microplate based assay (static flow regime)}

In the microplate based assay, biofilms were grown with no fluid shear and the anti-biofilm activity of peptides was assessed as previously described [55] with some modifications. Briefly, overnight cultures of $P$. aeruginosa PAO1 in TSB were adjusted at $5 \times$ $10^{7} \mathrm{CFU} / \mathrm{ml}$ turbidimetrically. This suspension was diluted in TSB (1:100) and $100 \mu \mathrm{l}$ aliquots were added to the wells of a 96-well plate. After $24 \mathrm{~h}$ incubation at $37{ }^{\circ} \mathrm{C}$, planktonic bacteria were removed by gently inverting the plate and then the biofilm-containing wells were washed with saline $(0.85 \% \mathrm{NaCl})$. The antimicrobial compound was serially diluted in Mueller Hinton $(\mathrm{MH})$ at final concentrations higher than its planktonic MIC and $200 \mu \mathrm{l}$ of each dilution was added to the wells. After $24 \mathrm{~h}$ incubation at $37{ }^{\circ} \mathrm{C}$, biofilms were stained with either MTT (Sigma, St. Louis, MO, USA) or crystal violet (CV). As control, duplicate biofilms were incubated with $\mathrm{MH}$ containing no antimicrobial.

To quantify the disinfection (or bactericidal) activity of the antimicrobials on the biofilms, the MTT assay [56] was used and performed as follows. After the treatment, the biofilms were rinsed with saline and $200 \mu \mathrm{l}$ of a $0.5 \mathrm{mg} / \mathrm{ml}$ dilution of MTT in $\mathrm{MH}$, was added to the wells. Incubation of biofilm with MTT was carried out during $4 \mathrm{~h}$ at $37{ }^{\circ} \mathrm{C}$ with no shaking. As a measure of cell viability, the conversion of MTT to a tetrazolium salt was determined by solubilizing the salt in $100 \mu \mathrm{l} /$ well of DMSO and reading the absorbance of the resulting solution at $540 \mathrm{~nm}$.

The ability of the antimicrobials to remove the biofilm attached to the microplate well was determined by $\mathrm{CV}$ staining [55, 57]. For this purpose, the treated biofilms were stained with $\mathrm{CV}$ during $5 \mathrm{~min}$ at room temperature. After the incubation, the excess of stain was rinsed with saline and the $\mathrm{CV}$ attached to biofilm was dissolved with ethanol $(95 \% \mathrm{v} / \mathrm{v})$. The absorbance was measured at $595 \mathrm{~nm}$.

Both the disinfection and removal activity of antimicrobials were expressed as "activity percentage", a 
parameter that was calculated using the following formula:

$$
\text { Activity Percentage }=\frac{(C-B)-(T-B)}{(C-B)} \times 100
$$

Where $C$ is the absorbance value of the control well with non-treated biofilm, $\mathrm{T}$ corresponds to the absorbance value of the well with treated biofilm and $B$ is the blank well (i.e. with no biofilm).

\section{CDC reactor based assay (dynamic flow regime)}

Biofilm growth was also induced under high fluid shear using the CDC-reactor (model CBR 90-1, BioSurface Technologies Corp., Bozeman, MT) as described before [58]. Briefly, $1 \mathrm{ml}$ of an overnight culture of $P$. aeruginosa PAO1 pMF230 was inoculated into $350 \mathrm{ml}$ of TSB and this suspension was used to fill the reactor chamber. After $24 \mathrm{~h}$ of growth in batch culture at $37^{\circ} \mathrm{C}$ with magnetic agitation, a continuous flow of TSB $(3 \mathrm{~g} / \mathrm{l})$ was applied to the reactor chamber at a rate of $11 \mathrm{ml} / \mathrm{min}$. Under these conditions, a dense biofilm develops on the surface of small disks called coupons that are constantly bathed in fresh culture medium. After $24 \mathrm{~h}$ incubation, the coupons were removed from the chamber and planktonic cells were eliminated by rinsing the coupons with saline. Then, the coupons were immersed in treated with $10 \mathrm{~mL}$ of $20 \mathrm{mM}$ phosphate buffer, $\mathrm{pH} 7$, containing different concentrations of the antimicrobial (1, 2 and 10 times their MIC) and incubated at $37{ }^{\circ} \mathrm{C}$ for 10 or $60 \mathrm{~min}$. Finally, the coupons were rinsed and processed for colony counting or microscopic visualization as follows.

For the colony counting method, biofilms were detached from the coupon surface by scraping coupons with a sterile wooden stick. Then, biofilm cells were suspended in saline, samples were homogenized at $20500 \mathrm{rpm}$ using Ultraturrax T2 (Janke \& Kunkel, IKA labortechnik; Staufen Germanyeterogeneitand plated out for counting. These count values were used to calculate the so called Log Density of the coupon which corresponds to the CFU $/ \mathrm{cm}^{2}$ of biofilm cells attached to the coupon. In turn, Log Density allowed the determination of $\log _{10}$ reduction (LR), which was defined as the difference of Log Density between the untreated and the treated biofilm. The experiments were performed in duplicate and two coupons were treated with the same peptide concentration in each experiment. The ANOVA Scheffé statistical test was used to assess the efficacy of the treatments.

For the microscopic assessment of anti-biofilm activity, biofilms grown and treated on coupons as detailed above were soaked in a $120 \mu \mathrm{M}$ solution of propidium iodide (PI, live/dead ${ }^{\circ}$ Baclight $^{\text {tm }}$ bacterial viability kit, Invitrogen, Carlsbad, CA, USA) in filter-sterilized distilled water and incubated for $15 \mathrm{~min}$ at room temperature. Then, coupons were rinsed in filter-sterilized distilled water and their surface was examined by fluorescence microscopy using FITC filter (green fluorescence: $\lambda_{\text {excitation }}, 499 \mathrm{~nm}$; $\lambda_{\text {emission, }} 519 \mathrm{~nm}$ ) and TRITC filter (red fluorescence: $\lambda_{\text {excitation }}, 552 \mathrm{~nm} ; \lambda_{\text {emission }}, 578 \mathrm{~nm}$ ). To evaluate the ability of the antimicrobial to penetrate into the biofilm structure, biofilms attached to coupons and treated with the most active antimicrobials were incubated with PI as detailed above and then examined with a confocal scanning laser microscope (Leica TCS NT, Solms, Germany). Samples were excited at $480 \mathrm{~nm}$ and the emission was measured at 500-550 $\mathrm{nm}$ for the green channel, whereas for the red channel the excitation and emission wavelengths were $568 \mathrm{~nm}$ and 590-650 nm, respectively. Microscope images were analyzed with the software Imaris $^{\circ} \times 64$ 5.7.2. (Bitplane, Zurich, Switzerland).

\section{Cytotoxicity assays}

Cytotoxicity was assayed on HeLa cells using the MTT [3(4,5-dimethylthiazoyl-2-yl) 2,5 diphenyltetrazolium bromide protocol [56]. Cells were grown in Dulbeccos's modified Eagle's medium (DMEM) and adjusted to a concentration of $10^{5}$ cells/ml (MTT) in 96 wells polystyrene plates. Plates were incubated for $24 \mathrm{~h}$ at $37{ }^{\circ} \mathrm{C}$ in $5 \% \mathrm{CO}_{2}$, then supplemented with increasing amounts of peptides diluted in $2 \mathrm{mM}$ Hepes $\mathrm{pH} 7.2$, and incubation carried on for $24 \mathrm{~h}$ under the same conditions. After this time, filter-sterilized MTT was added in different plates. After $3 \mathrm{~h}$, the content of the wells was gently solved and mixed with $100 \mu \mathrm{l}$ of DMSO (MTT). Absorbance was measured at $540 \mathrm{~nm}$. Compound cytotoxicity was expressed as LC50, the concentration of the compound that is lethal to $50 \%$ of the cells.

\section{Abbreviations \\ MIC: Minimum inhibitory concentration; MBC: Minimum bactericidal concentration; AMP: Antimicrobial peptides; MTT: 3-(4,5-dimethylthiazol-2-yl)- 2,5-diphenyltetrazolium bromide; CV: Crystal violet; CLSM: Confocal laser scanning microscopy; CFU: Colony forming unit; TSB: Tryptic soy broth; MH: Mueller Hinton; LB: Luria Bertani; GFP: Green fluorescence protein; CLSI: Clinical Laboratory Standard; NCCLS: National Committee for Clinical Laboratory Standard; LR: Log10 reduction; PI: Propidium iodide; DMEM: Dulbeccos's modified Eagle's medium; LC50: Concentration of the compound that is lethal to $50 \%$ of the cells.}

\section{Competing interests}

The authors declare that they have no competing interests.

\section{Authors' contributions}

GMT and KL designed the peptide sequences and GMT conceived and designed the study. RFE participate in killing assays and in microplates biofilm test. SSG designed and carried out most of the experiment under the supervision of GMT, PS and BP. SSG and GMT edited the manuscript. All authors read and approved the final manuscript.

\section{Acknowledgements}

G.M.T. was funded by a grant from Proyectos de Investigación Universidad de Navarra (PIUNA-P2011-17), Spain. S.S.G. and R.F.E were recipients of doctoral fellowships from Gobierno Vasco, Spain. 


\section{Author details}

'Department of Microbiology, University of Navarra, Irunlarrea 1, E-31008 Pamplona, Spain. ${ }^{2}$ Center for Biofilm Engineering, Montana State University, Bozeman, MT, USA. ${ }^{3}$ Institute of Molecular Biosciences, Biophysics Division, University of Graz, Graz, Austria. ${ }^{4}$ Present address: Susana Sánchez-Gómez, Bionanoplus, 31110 Noain, Spain.

\section{Received: 18 March 2015 Accepted: 26 June 2015}

Published online: 07 July 2015

\section{References}

1. Lodise TP, Patel N, Kwa A, Graves J, Furuno JP, Graffunder E, et al. Predictors of 30-day mortality among patients with Pseudomonas aeruginosa bloodstream infections: impact of delayed appropriate antibiotic selection. Antimicrob Agents Chemother. 2007;51:3510-5.

2. Tam VH, Rogers CA, Chang KT, Weston JS, Caeiro JP, Garey KW. Impact of multidrug-resistant Pseudomonas aeruginosa bacteremia on patient outcomes. Antimicrob Agents Chemother. 2010;54:3717-22.

3. Lewis K. Riddle of biofilm resistance. Antimicrob Agents Chemother. 2001:45:999-1007.

4. Davey ME, O'Toole GA. Microbial biofilms: from ecology to molecular genetics. Microbiol Mol Biol Rev. 2000;64:847-67.

5. Donlan RM, Costerton JW. Biofilms: survival mechanisms of clinically relevant microorganisms. Clin Microbiol Rev. 2002;15:167-93.

6. Stewart PS, Costerton JW. Antibiotic resistance of bacteria in biofilms. Lancet. 2001:358:135-8.

7. Jenssen $H$, Hamill P, Hancock REW. Peptide antimicrobial agents. Clin Microbiol Rev. 2006;19:491-511.

8. Lohner K. New strategies for novel antibiotics: peptides targeting bacterial cell membranes. Gen Physiol Biophys. 2009;28:105-16.

9. Navon-Venezia S, Feder R, Gaidukov L, Carmeli Y, Mor A. Antibacterial properties of dermaseptin $\mathrm{S} 4$ derivatives with in vivo activity. Antimicrob Agents Chemother. 2002;46:689-94.

10. Zhang L, Parente J, Harris SM, Woods DE, Hancock REW, Falla TJ. Antimicrobial peptide therapeutics for cystic fibrosis. Antimicrob Agents Chemother. 2005:49:2921-7.

11. Batoni G, Maisetta G, Brancatisano FL, Esin S, Campa M. Use of antimicrobial peptides against microbial biofilms: advantages and limits. Curr Med Chem. 2011;18:256-79.

12. Gifford JL, Hunter HN, Vogel HJ. Lactoferricin: a lactoferrin-derived peptide with antimicrobial, antiviral, antitumor and immunological properties. Cell Mol Life Sci. 2005;62:2588-98.

13. Orsi N. The antimicrobial activity of lactoferrin: current status and perspectives. Biometals. 2004;17:189-96.

14. Sanchez-Gomez S, Lamata M, Leiva J, Blondelle SE, Jerala R, Andra J, et al. Comparative analysis of selected methods for the assessment of antimicrobial and membrane-permeabilizing activity: a case study for lactoferricin derived peptides. BMC Microbiol. 2008:8:196

15. Sanchez-Gomez S, Japelj B, Jerala R, Moriyon I, Fernández Alonso M, Leiva J, et al. Structural features governing the activity of lactoferricin-derived peptides that act in synergy with antibiotics against Pseudomonas aeruginosa in vitro and in vivo. Antimicrob Agents Chemother. 2011;55:218-28.

16. Zweytick D, Deutsch G, Andra J, Blondelle SE, Vollmer E, Jerala R, et al. Studies on lactoferricin-derived Escherichia coli membrane-active peptides reveal differences in the mechanism of $\mathrm{N}$-acylated versus nonacylated peptides. J Biol Chem. 2011;286:21266-76.

17. Martinez de Tejada G, Sanchez-Gomez S, Razquin-Olazaran I, Kowalski I, Kaconis Y, Heinbockel L, et al. Bacterial cell wall compounds as promising targets of antimicrobial agents I. Antimicrobial peptides and lipopolyamines. Curr Drug Targets. 2012;13:1121-30.

18. Zorko M, Japelj B, Hafner-Bratkovic I, Jerala R. Expression, purification and structural studies of a short antimicrobial peptide. Biochim Biophys Acta. 2009;1788:314-23.

19. Andra J, Lohner K, Blondelle SE, Jerala R, Moriyon I, Koch MHJ, et al. Enhancement of endotoxin neutralization by coupling of a C12-alkyl chain to a lactoferricin-derived peptide. Biochem J. 2005;385:135-43.

20. Zweytick D, Pabst G, Abuja PM, Jilek A, Blondelle SE, Andra J, et al. Influence of $\mathrm{N}$-acylation of a peptide derived from human lactoferricin on membrane selectivity. Biochim Biophys Acta. 2006;1758:1426-35.
21. Japelj B, Zorko M, Majerle A, Pristovsek P, Sanchez-Gomez S, Martinez de Tejada G, et al. The acyl group as the central element of the structural organization of antimicrobial lipopeptide. J Am Chem Soc. 2007;129:1022-3.

22. Brandenburg K, Howe J, Sanchez-Gomez S, Garidel P, Roessle M, Andra J, et al. Effective antimicrobial and anti-endotoxin activity of cationic peptides based on lactoferricin: a biophysical and microbiological study. Antiinfect Agents Med Chem. 2010;9:9-22.

23. Radzishevsky IS, Rotem S, Zaknoon F, Gaidukov L, Dagan A, Mor A. Effects of acyl versus aminoacyl conjugation on the properties of antimicrobial peptides. Antimicrob Agents Chemother. 2005;49:2412-20.

24. Jiang Z, Vasil Al, Gera L, Vasil ML, Hodges RS. Rational design of a-helical antimicrobial peptides to target gram-negative pathogens, acinetobacter baumannii and pseudomonas aeruginosa: utilization of charge, "Specificity Determinants", total hydrophobicity, hydrophobe type and location as design parameters to improve the therapeutic ratio. Chem Biol Drug Des. 2011;77:225-40.

25. Rathinakumar R, Walkenhorst WF, Wimley WC. Broad-spectrum antimicrobial peptides by rational combinatorial design and high-throughput screening: the importance of interfacial activity. J Am Chem Soc. 2009;131:7609-17.

26. Rathinakumar R, Wimley WC. Biomolecular engineering by combinatorial design and high-throughput screening: small, soluble peptides that permeabilize membranes. J Am Chem Soc. 2008;130:9849-58.

27. Yeaman MR. Mechanisms of antimicrobial peptide action and resistance Pharmacol Rev. 2003;55:27-55.

28. Chen Y, Guarnieri MT, Vasil Al, Vasil ML, Mant CT, Hodges RS. Role of peptide hydrophobicity in the mechanism of action of -helical antimicrobial peptides. Antimicrob Agents Chemother. 2007;51:1398-406.

29. Kustanovich I. Structural requirements for potent versus selective cytotoxicity for antimicrobial dermaseptin S4 derivatives. J Biol Chem. 2002;277:16941-51.

30. Zelezetsky I, Pag U, Sahl H-G, Tossi A. Tuning the biological properties of amphipathic a-helical antimicrobial peptides: rational use of minimal amino acid substitutions. Peptides. 2005;26:2368-76.

31. Jiang Z, Vasil Al, Hale JD, Hancock REW, Vasil ML, Hodges RS. Effects of net charge and the number of positively charged residues on the biological activity of amphipathic a-helical cationic antimicrobial peptides. Biopolymers. 2008;90:369-83.

32. Gopal R, Kim YG, Lee JH, Lee SK, Chae JD, Son BK, et al. Synergistic effects and antibiofilm properties of chimeric peptides against multidrug-resistant Acinetobacter baumannii strains. Antimicrob Agents Chemother. 2014;58:1622-9.

33. Zairi A, Ferrieres L, Latour-Lambert P, Beloin C, Tangy F, Ghigo J-M, et al. In vitro activities of dermaseptins K4S4 and K4K20S4 against Escherichia coli, Staphylococcus aureus, and Pseudomonas aeruginosa planktonic growth and biofilm formation. Antimicrob Agents Chemother. 2014;58:2221-8.

34. Beckloff N, Laube D, Castro T, Furgang D, Park S, Perlin D, et al. Activity of an antimicrobial peptide mimetic against planktonic and biofilm cultures of oral pathogens. Antimicrob Agents Chemother. 2007:51:4125-32.

35. Roveta S, Marchese A, Schito GC. Activity of daptomycin on biofilms produced on a plastic support by Staphylococcus spp. Int J Antimicrob Agents. 2008:31:321-8.

36. Wei GX. Effect of MUC7 peptides on the growth of bacteria and on Streptococcus mutans biofilm. J Antimicrob Chemother. 2006:57:1100-9.

37. Singh PK, Parsek MR, Greenberg EP, Welsh MJ. A component of innate immunity prevents bacterial biofilm development. Nature. 2002;417:552-5.

38. Singh PK. Iron sequestration by human lactoferrin stimulates $P$. aeruginosa surface motility and blocks biofilm formation. Biometals. 2004;17:267-70.

39. Kamiya $H$, Ehara T, Matsumoto T. Inhibitory effects of lactoferrin on biofilm formation in clinical isolates of Pseudomonas aeruginosa. J Infect Chemother. 2012;18:47-52

40. Arslan SY, Leung KP, Wu CD. The effect of lactoferrin on oral bacterial attachment. Oral Microbiol Immunol. 2009:24:411-6.

41. Berlutti F, Ajello M, Bosso P, Morea C, Petrucca A, Antonini G, et al. Both lactoferrin and iron influence aggregation and biofilm formation in Streptococcus mutans. Biometals. 2004;17:271-8.

42. Caraher EM, Gumulapurapu K, Taggart CC, Murphy P, McClean S, Callaghan $M$. The effect of recombinant human lactoferrin on growth and the antibiotic susceptibility of the cystic fibrosis pathogen Burkholderia cepacia complex when cultured planktonically or as biofilms. J Antimicrob Chemother. 2007;60:546-54.

43. O'May CY, Sanderson K, Roddam LF, Kirov SM, Reid DW. Iron-binding 3compounds impair Pseudomonas aeruginosa biofilm formation, especially under anaerobic conditions. J Med Microbiol. 2009:58:765-73. 
44. Wakabayashi H, Yamauchi K, Kobayashi T, Yaeshima T, Iwatsuki K, Yoshie H. Inhibitory effects of lactoferrin on growth and biofilm formation of Porphyromonas gingivalis and Prevotella intermedia. Antimicrob Agents Chemother. 2009;53:3308-16.

45. Xu G, Xiong W, Hu Q, Zuo P, Shao B, Lan F, et al. Lactoferrin-derived peptides and Lactoferricin chimera inhibit virulence factor production and biofilm formation in Pseudomonas aeruginosa. J Appl Microbiol. 2010;109:1311-8.

46. la Fuente-Núñez de C, Reffuveille F, Haney EF, Straus SK, Hancock REW. Broad-spectrum anti-biofilm peptide that targets a cellular stress response. PLoS Pathog. 2014;10:e1004152.

47. la Fuente-Núñez de C, Korolik V, Bains M, Nguyen U, Breidenstein EBM, Horsman S, et al. Inhibition of bacterial biofilm formation and swarming motility by a small synthetic cationic peptide. Antimicrob Agents Chemother. 2012;56:2696-704.

48. Nagant C, Seil M, Nachtergael A, Dulanto S, Dehaye JP. Contribution of the production of quormones to some phenotypic characteristics of Pseudomonas aeruginosa clinical strains. J Med Microbiol. 2013;62:951-8.

49. Hill D, Rose B, Pajkos A, Robinson M, Bye P, Bell S, et al. Antibiotic susceptabilities of Pseudomonas aeruginosa isolates derived from patients with cystic fibrosis under aerobic, anaerobic, and biofilm conditions. J Clin Microbiol. 2005;43:5085-90.

50. Pamp SJ, Gjermansen M, Johansen HK, Tolker-Nielsen T. Tolerance to the antimicrobial peptide colistin in Pseudomonas aeruginosa biofilms is linked to metabolically active cells, and depends on the pmr and mexAB-oprM genes. Mol Microbiol. 2008;68:223-40.

51. Herrmann G, Yang L, Wu H, Song Z, Wang H, Høiby N, et al. ColistinTobramycin combinations are superior to monotherapy concerning the killing of biofilm Pseudomonas aeruginosa. J Infect Dis. 2010;202:1585-92.

52. Eckert R, Brady KM, Greenberg EP, Qi F, Yarbrough DK, He J, et al. Enhancement of antimicrobial activity against Pseudomonas aeruginosa by coadministration of $\mathrm{G} 10 \mathrm{KHC}$ and tobramycin. Antimicrob Agents Chemother. 2006;50:3833-8.

53. Banin E, Brady KM, Greenberg EP. Chelator-induced dispersal and killing of Pseudomonas aeruginosa cells in a biofilm. Appl Environ Microbiol. 2006;72:2064-9.

54. Nivens DE, Ohman DE, Williams J, Franklin MJ. Role of alginate and its O acetylation in formation of Pseudomonas aeruginosa microcolonies and biofilms. J Bacteriol. 2001;183:1047-57.

55. Pitts B, Hamilton MA, Zelver N, Stewart PS. A microtiter-plate screening method for biofilm disinfection and removal. J Microbiol Methods. 2003:54:269-76.

56. Andra J, Monreal D, Martinez de Tejada G, Olak C, Brezesinski G, Gomez SS, et al. Rationale for the design of shortened derivatives of the NK-lysin-derived antimicrobial peptide NK-2 with improved activity against Gram-negative pathogens. J Biol Chem. 2007;282:14719-28.

57. O'Toole GA, Kolter R. Flagellar and twitching motility are necessary for Pseudomonas aeruginosa biofilm development. Mol Microbiol. 1998;30:295-304.

58. Goeres DM, Loetterle LR, Hamilton MA, Murga R, Kirby DW, Donlan RM. Statistical assessment of a laboratory method for growing biofilms. Microbiology (Reading, Engl). 2005;151:757-62.

59. Wimley WC, Creamer TP, White SH. Solvation energies of amino acid side chains and backbone in a family of host-guest pentapeptides. Biochemistry. 1996;35:5109-24.

60. Snider C, Jayasinghe S, Hristova K, White SH. MPEx: a tool for exploring membrane proteins. Protein Sci. 2009;18:2624-8.

\section{Submit your next manuscript to BioMed Central and take full advantage of:}

- Convenient online submission

- Thorough peer review

- No space constraints or color figure charges

- Immediate publication on acceptance

- Inclusion in PubMed, CAS, Scopus and Google Scholar

- Research which is freely available for redistribution 